\title{
Serum Levels After Everolimus-Stent Implantation and Paclitaxel-Balloon Angioplasty in an Infant with Recurrent Pulmonary Vein Obstruction After Repaired Total Anomalous Pulmonary Venous Connection
}

\author{
Matthias J. Müller • Ulrich Krause • \\ Thomas Paul · Heike E. Schneider
}

Received: 18 March 2011/Accepted: 7 July 2011 / Published online: 28 July 2011

(C) The Author(s) 2011. This article is published with open access at Springerlink.com

\begin{abstract}
Everolimus-eluting stents and paclitaxel-coated balloons are used in the interventional treatment of coronary artery disease in adults to reduce the restenosis rate and in small-vessel disease. Both substances are released into the circulation. We report systemic drug exposure after implantation of one everolimus-eluting stent and dilation with one paclitaxel-coated balloon in an 8-month-old infant, which was used as an innovative therapy for recurrent pulmonary vein stenosis.
\end{abstract}

Keywords Pulmonary venous obstruction - Everolimus stent $\cdot$ Paclitaxel balloon - Total anomalous pulmonary venous connection

\section{Background}

Total anomalous pulmonary venous connection (TAPVC) is a rare congenital heart defect, in which all pulmonary veins (PVs) connect to systemic veins, right atrium, or the coronary sinus [11]. Before surgical treatment was established, the majority of these children died within the first few months of life. Based on progress in surgical and intensive care expertise, early mortality was significantly reduced [11]. In the current era, late mortality is of concern. Late mortality is typically associated with postoperative pulmonary venous obstruction (PVO). The incidence of postoperative PVO that requires reintervention is about $14.8 \%$. For patients with initial TAPVC surgery and

M. J. Müller ( $ه)$ · U. Krause · T. Paul · H. E. Schneider Department for Pediatric Cardiology and Intensive Care Medicine, Georg-August-University Göttingen, Robert-Koch-Str. 40, 37075 Göttingen, Germany e-mail: matthias.mueller@med.uni-goettingen.de postoperative PVO, 3-year survival is only 58.7\% [11]. PVO may be anatomically localized at the surgical anastomosis site(s) or diffusely in the branch PVs [2]. Conventional therapy options for PVO include reoperation, catheter intervention with balloon or cutting balloon dilations, or the implantation of bare-metal stents. A high restenosis rate limits the success of these methods $[2,6]$. Histopathologic examination in patients with PVO has revealed a neoproliferative process involving myofibroblasts [8]. The local application of antiproliferative substances, such as everolimus or paclitaxel, could be a new therapeutic option for recurrent PVO. Both antiproliferative substances are established medications for use with drug-eluting devices to avoid restenosis in adults with coronary artery disease and in-stent restenosis or smallvessel disease $[3,10]$. Data on their use in children, with respect to their success and systemic effects, are limited.

We report systemic drug levels in an 8-month-old infant after implantation of an everolimus-eluting stent and balloon dilation with a paclitaxel-coated balloon for recurrent PVO.

\section{Case Report}

A 19-day-old boy was transferred to our tertiary cardiac center with cyanosis and heart failure symptoms. Unobstructed supracardiac TAPVC draining via a vertical vein to the innominate vein was diagnosed echocardiographically. Surgical repair included a side-to-side anastomosis of the common PV and the left atrium. Significant bilateral PVO extending diffusely into the branch $\mathrm{PVs}$ required reoperation at the age of 4 months. The intraoperative situs revealed excessive tissue proliferation. Although the technique of sutureless in situ pericardial repair [4] had been applied, 
PVO recurred bilaterally, involving PV segments distal to the anastomosis. At the age of 6 months, stenotic regions of the right and left PVs were balloon dilated, and bare-metal stents (Driver Sprint, Medtronic Inc., Minneapolis, MN) were implanted in the right lower and left upper PVs. Despite combined treatment with aspirin and clopidogrel, recurrent PVO required reintervention 1 month later, including implantation of an additional bare-metal stent into the right lower PV and balloon dilation of significant in-stent restenosis of the left upper PV stent.

At the age of 8 months, PVO recurred bilaterally in this now 4.6-kg infant with a body surface area (BSA) of $0.28 \mathrm{~m}^{2}$. We chose to use drug-eluting materials for further intervention. One everolimus-eluting stent (Xience ${ }^{\circledR} \mathrm{V}$, Abbott Laboratories, Abbott Park, IL), coated with $113 \mu \mathrm{g}$ of the drug, was implanted into the right distal lower PV due to distal stenosis. Additionally, significant in-stent restenosis was observed within the stent in the left upper PV. Therefore, a paclitaxel-eluting balloon (SeQuent ${ }^{\circledR}$ Please, Braun Melsungen AG, Berlin, Germany), coated with $640 \mu \mathrm{g}$ of paclitaxel, was advanced through a guiding catheter to avoid the delamination of paclitaxel and loss into the bloodstream. Time for inflation of the paclitaxel-coated balloon was $60 \mathrm{~s}$ to assure local drug delivery (Fig. 1a-c). Significant gradient reduction was achieved and right ventricular systolic pressure decreased to half-systemic levels. However, as in the previous catheterizations, progressive narrowing of the distal PVs and loss of PV segments were observed.

\section{Serum Drug Levels}

After implantation of the everolimus-eluting stent, our patient was exposed to a maximal everolimus dose of
$0.40 \mathrm{mg} / \mathrm{m}^{2}$ BSA. The serum everolimus level $24 \mathrm{~h}$ after stent implantation was low, at $0.70 \mathrm{ng} / \mathrm{mL}$, and decreased to $0.40 \mathrm{ng} / \mathrm{mL}$ at $48 \mathrm{~h}$ and to $0.30 \mathrm{ng} / \mathrm{mL}$ at $72 \mathrm{~h}$ (Table 1). After $48 \mathrm{~h}$, everolimus levels were below the lower laboratory limit $(<0.5 \mathrm{ng} / \mathrm{mL})$ at our institution but still reliably detectable by repeated mass spectrometry.

The maximal possible dose of paclitaxel that our patient received could have been $2.29 \mathrm{mg} / \mathrm{m}^{2} \mathrm{BSA}$, assuming that $100 \%(640 \mu \mathrm{g})$ of the drug was released into the circulation. Serum level at $24 \mathrm{~h}$ was already low at $0.59 \mathrm{ng} / \mathrm{mL}$ and decreased to 0.40 and $0.34 \mathrm{ng} / \mathrm{mL}$ at 48 and $72 \mathrm{~h}$, respectively, as assessed by combined liquid chromatography and mass spectrometry (Fig. 2). As for everolimus, the levels after $48 \mathrm{~h}$ were also below the lower limit $(<0.5 \mathrm{ng} / \mathrm{mL})$ of the laboratory.

\section{Assessment of Potential Drug Side Effects and Further Clinical Course}

Complete blood count, differential count, creatinine, C-reactive protein, and liver enzymes did not change compared to the laboratory parameters obtained prior to catheter intervention. Drug toxicity such as leukopenia, hyperglycemia, mucositis, gastrointestinal symptoms, renal impairment, or worsening infection while on antibiotic treatment for preexisting pneumonia was not observed.

At the age of nearly 9 months, 19 days after the last catheter intervention, the patient died due to right heart failure following refractory and progressive narrowing of the entire PV system. The parents had declined further treatment with combined heart-lung transplantation. An autopsy to examine the PV system was denied.
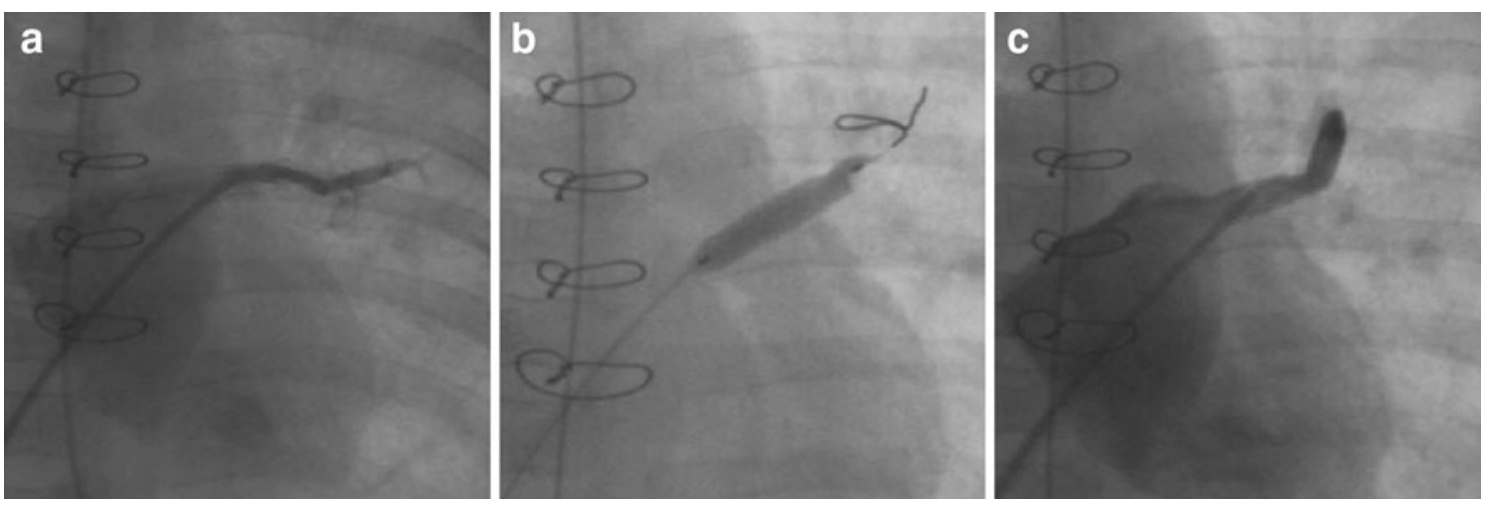

Fig. 1 Angiography of an 8-month-old boy with pulmonary venous obstruction after side-to-side anastomosis for total anomalous pulmonary venous connection and stent implantations into the left upper and right lower PVs. a Selective contrast injection into the left upper PV demonstrated significant in-stent-restenosis within the bare- metal stent that had been implanted 1 month earlier. b Balloon angioplasty with a paclitaxel-coated balloon after predilation with a regular balloon of the in-stent restenosis. c Contrast injection after balloon dilation shows significant improvement of the diameter of the stented vessel 
Table 1 Device, drug amount, maximal possible exposure to the patient and serum concentrations of the paclitaxel-coated balloon and everolimus-eluting stent 24,48 , and $72 \mathrm{~h}$ after interventional treatment

\begin{tabular}{|c|c|c|c|c|c|}
\hline \multirow[t]{2}{*}{ Device } & \multirow{2}{*}{$\begin{array}{l}\text { Device drug } \\
\text { amount }\end{array}$} & \multirow[t]{2}{*}{ Maximal possible exposure } & \multicolumn{3}{|c|}{ Serum concentrations after treatment } \\
\hline & & & $24 \mathrm{~h}$ & $48 \mathrm{~h}$ & $72 \mathrm{~h}$ \\
\hline Paclitaxel-coated balloon $(4 \mathrm{~mm} \times 17 \mathrm{~mm})$ & $640 \mu \mathrm{g}$ & $2.29 \mathrm{mg} / \mathrm{m}^{2}(0.139 \mathrm{mg} / \mathrm{kg})$ & $0.59 \mathrm{ng} / \mathrm{mL}$ & $0.40 \mathrm{ng} / \mathrm{mL}$ & $0.34 \mathrm{ng} / \mathrm{mL}$ \\
\hline Everolimus-eluting stent $(4 \mathrm{~mm} \times 18 \mathrm{~mm})$ & $113 \mu \mathrm{g}$ & $0.4 \mathrm{mg} / \mathrm{m}^{2}(0.025 \mathrm{mg} / \mathrm{kg})$ & $0.70 \mathrm{ng} / \mathrm{mL}$ & $0.40 \mathrm{ng} / \mathrm{mL}$ & $0.30 \mathrm{ng} / \mathrm{mL}$ \\
\hline
\end{tabular}

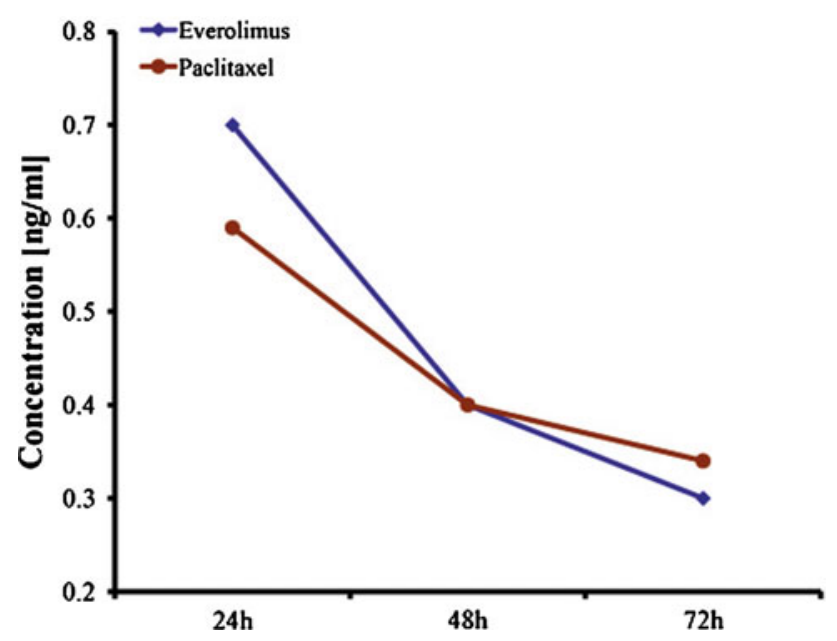

Fig. 2 Plasma concentrations of everolimus and paclitaxel $(\mathrm{ng} / \mathrm{mL})$ after implantation of one everolimus-eluting stent and balloon dilatation with a paclitaxel-coated balloon for recurrent PV stenosis and in-stent-stenosis in an 8-months-old infant at 24, 48, and $72 \mathrm{~h}$

\section{Discussion}

Recurrent PVO after repair of TAPVC has a poor prognosis [11]. After unsuccessful conventional surgical and interventional treatment of PVO, we attempted the local application of the antiproliferative substances everolimus and paclitaxel to prevent restenosis due to recurrent PVO in an infant. Whether these substances can provide new therapeutic options for this form of progressive PVO remains unclear and demands further investigation. As our patient subsequently died of progressive obliteration of the PV bed, which was likely caused by proliferating myofibroblasts, the question arises of whether systemic antiproliferative therapy might be a potential treatment option in these patients with relentless progressive PVO [5, 7, 8].

For this patient, we chose two different antiproliferative agents to reduce potential drug toxicities. In adults with advanced malignancies, the concomitant use of everolimus and paclitaxel is an effective treatment strategy, due to the synergistic antiproliferative effects achieved [1]. Despite the fact that both drugs are eliminated via the same hepatic pathway, no pharmacokinetic drug interactions were described, and neutropenia was the only toxicity detected after the application of systemic effective dosages in adults
[1]. We did not observe any systemic toxic side effects in our patient. Therefore, we assume that his death was unrelated to the drugs administered during intervention but was a result of his underlying progressive PVO.

Currently, little is known regarding systemic drug release from drug-eluting materials in infants. In adults, peak levels are reached after 10-60 min after everolimuseluting stent implantation. Terminal half-life is dose dependent, and the drug can be detected for up to 30 days [12]. We documented a low level of everolimus, far below the immunosuppressive therapeutic range of $3-6 \mathrm{ng} / \mathrm{mL}$, $24 \mathrm{~h}$ postintervention in this infant. The everolimus level subsequently decreased further.

Using paclitaxel-eluting balloons, a study in animals [9] suggested that only $15.6 \pm 13.1 \%$ of the dose of the coated balloon could be measured in the vessel wall and that about $80 \%$ of the drug is released into the circulation during implantation. With this assumption, our patient received an immediate dose of approximately $512 \mu \mathrm{g}$ paclitaxel, a systemic exposure of $1.83 \mathrm{mg} / \mathrm{m}^{2}$ BSA. This amount would represent a low but considerable total dose compared to typical doses applied in pediatric oncology, which range from 3 to $5 \mathrm{mg} / \mathrm{m}^{2}$ over $24 \mathrm{~h}$. In a previous study, a similar paclitaxel-coated balloon with a total paclitaxel dose of $754 \mu \mathrm{g}$ was used for the dilation of congenital PVO in a 4-week-old newborn [6]. Paclitaxel levels were measured up to $4 \mathrm{~h}$ after balloon dilation. Four hours after intervention, the highest plasma level of $20.18 \mathrm{ng} / \mathrm{mL}$ was detected: the systemic therapeutic level of $85 \mathrm{ng} / \mathrm{mL}$ was not reached. Decreasing paclitaxel levels were not reported. Our results document very low serum levels of paclitaxel at $24 \mathrm{~h}$ that were insignificant but still detectable at $72 \mathrm{~h}$.

Here, we examined, for the first time, everolimus and paclitaxel serum levels in an infant over a 72-h interval after interventional treatment of relentless PVO. Despite the combined administration of these two antiproliferative agents, we may assume that systemic adverse effects were unlikely because subtherapeutic serum levels were already documented $24 \mathrm{~h}$ after the application of both drugs.

Open Access This article is distributed under the terms of the Creative Commons Attribution Noncommercial License which permits any noncommercial use, distribution, and reproduction in any medium, provided the original author(s) and source are credited. 


\section{References}

1. Campone M, Levy V, Bourbouloux E, Berton Rigaud D, Bootle D, Dutreix C, Zoellner U, Shand N, Calvo F, Raymond E (2009) Safety and pharmacokinetics of paclitaxel and the oral mTOR inhibitor everolimus in advanced solid tumours. Br J Cancer 100:315-321

2. Devaney EJ, Chang AC, Ohye RG, Bove EL (2006) Management of congenital and acquired pulmonary vein stenosis. Ann Thorac Surg 81:992-995 (discussion 995-996)

3. Gabardi S, Baroletti SA (2010) Everolimus: a proliferation signal inhibitor with clinical applications in organ transplantation, oncology, and cardiology. Pharmacotherapy 30:1044-1056

4. Lacour-Gayet F, Zoghbi J, Serraf AE, Belli E, Piot D, Rey C, Marcon F, Bruniaux J, Planche C (1999) Surgical management of progressive pulmonary venous obstruction after repair of total anomalous pulmonary venous connection. J Thorac Cardiovasc Surg 117:679-687

5. Latson LA, Prieto LR (2007) Congenital and acquired pulmonary vein stenosis. Circulation 115:103-108

6. Mueller GC, Dodge-Khatami A, Weil J (2010) First experience with a new drug-eluting balloon for the treatment of congenital pulmonary vein stenosis in a neonate. Cardiol Young 20:455-458

7. Riedlinger WF, Juraszek AL, Jenkins KJ, Nugent AW, Balasubramanian S, Calicchio ML, Kieran MW, Collins T (2006)
Pulmonary vein stenosis: expression of receptor tyrosine kinases by lesional cells. Cardiovasc Pathol 15:91-99

8. Sadr IM, Tan PE, Kieran MW, Jenkins KJ (2000) Mechanism of pulmonary vein stenosis in infants with normally connected veins. Am J Cardiol 86:577-579, A510

9. Scheller B, Speck U, Abramjuk C, Bernhardt U, Bohm M, Nickenig G (2004) Paclitaxel balloon coating, a novel method for prevention and therapy of restenosis. Circulation 110:810-814

10. Scheller B, Hehrlein C, Bocksch W, Rutsch W, Haghi D, Dietz U, Bohm M, Speck U (2006) Treatment of coronary in-stent restenosis with a paclitaxel-coated balloon catheter. N Engl J Med 355:2113-2124

11. Seale AN, Uemura H, Webber SA, Partridge J, Roughton M, Ho SY, McCarthy KP, Jones S, Shaughnessy L, Sunnegardh J, Hanseus K, Berggren H, Johansson S, Rigby ML, Keeton BR, Daubeney PE (2010) Total anomalous pulmonary venous connection: morphology and outcome from an international population-based study. Circulation 122:2718-2726

12. Wiemer M, Seth A, Chandra P, Neuzner J, Richardt G, Piek JJ, Desaga M, Macaya C, Bol CJ, Miquel-Hebert K, De Roeck K, Serruys PW (2008) Systemic exposure of everolimus after stent implantation: a pharmacokinetic study. Am Heart J 156:751 e751-e757 